Review

\title{
Embracing Pharmacy E-Learning: Models of Success
}

\author{
Jaclyn A. Jeffries ${ }^{1 *}$, Pamela R. Jeffries ${ }^{2}$, John B. Hertig ${ }^{3}$ and Kyle E. Hultgren ${ }^{3}$
}

1 Health First, 1350 South Hickory Street, Melbourne, FL 32901, USA

2 School of Nursing, Johns Hopkins University, 525 N. Wolfe Street, Baltimore, MD 21205, USA;

E-Mail: pjeffri2@jhu.edu

3 College of Pharmacy's Center for Medication Safety Advancement, Purdue University, 6640 Intech Boulevard, Suite 120 Indianapolis, IN 46278, USA; E-Mails: jhertig@purdue.edu (J.B.H.); khultgre@purdue.edu (K.E.H.)

* Author to whom correspondence should be addressed; E-Mail: jaclyn.jeffries@health-first.org; Tel.: +1-321-434-1918; Fax: +1-321-434-8734.

Received: 28 June 2013; in revised form: 27 July 2013 / Accepted: 1 August 2013 /

Published: 9 August 2013

Abstract: Traditionally, education has revolved around the idea of a learner being taught in a physical classroom setting. With recent technological developments and the "immediate results" world we now live in, elearning has become much more common. Students and professionals are now able to access and acquire lectures, tests, certifications and degrees online. The Purdue University College of Pharmacy's Center for Medication Safety Advancement has developed three eresources to enhance medication safety: The Veterans Affairs Yellow Belt Lean Certification Course, the Medication Safety Essentials Continuing Education Modules, and the Virtual Clean Room Simulation Certificate. These three modalities offer valuable content for additional knowledge, training and certification at a convenient location-your computer.

Keywords: elearning; eportfolio; eresources; reflective practitioners; evaluation; just-in-time resources

\section{Introduction}

Medication safety continues to be a priority in healthcare. In hospitals alone, over 770,000 people are injured or die each year from adverse drug events (ADEs) [1-3]. The result is a financial impact of up to 
$\$ 5.6$ million each year per hospital depending on a hospital's size [4,5]. This estimate does not include costs associated with re-admissions, malpractice and litigation, or other injuries to patients as the result of ADEs. Further, this does not account for the impact ADEs have in the community setting where data is even more difficult to quantify. Every year, hospitals spend an estimated $\$ 1.56-\$ 5.6$ billion to treat patients who suffered as a result of ADEs during hospitalization in the United States (US) alone [4-7].

Even though research on the cost and causes of ADEs in the USA have been reported for years in the literature, the problem was brought to the attention of a larger audience in 2000 when the first of a series of reports was released by the Institute of Medicine (IOM): "To Err is Human". The future reports "Crossing the Quality Chasm" and "Preventing Medication Errors" were subsequently released. These IOM reports seek to outline, highlight, and address the medication error sensation, the barriers preventing improvement, and the strategies that need to be implemented to make medication use safer [8-10].

Accrediting and reimbursement organizations have added more standards that the USA healthcare system is expected to comply to. The dynamic nature of healthcare; additional therapies, new indications, better diagnostics, etc., and the ability to deliver up-to-date information has become increasingly difficult. Maxwell et al. viewed this influx of information from a prescribing standpoint; these findings can be extrapolated to several different educational arenas. Elearning allows educators to distribute accurate content and update it as necessary, as well as standardize what learners are being taught. The individuals completing the elearning exercises are able to complete the course or module on an individual basis at their own pace, as well as access the content anywhere, anytime [11].

The Purdue University College of Pharmacy's Center for Medication Safety Advancement (CMSA) recognized specific areas that could be targeted to help decrease medication errors that would serve the citizens of Indiana, the USA, and the world. Innovation and collaboration between CMSA and other health-care practitioners has led to the development of three elearning courses to promote safe medication use and advance CMSA's vision of making safe medication use common practice. By providing these materials online, interested individuals can conveniently access the materials provided, further their education and training, and become certified in a particular area, thereby standardizing processes in order to create safer health-care practices.

\section{The Veterans Affairs Yellow Belt Lean Certification Course}

In 2009, the CMSA was presented with a valuable opportunity to partner with the United States Department of Veteran Affairs (VA) Veteran's Engineering Resource Center (VERC) in Indianapolis, Indiana to create a Process Improvement Science and Systems Redesign curriculum for the staff of the VA. The primary focus of the program was to expand the capability of staff to systematically improve patient care and to grow their capacity for performing this work. The Systems Redesign course focuses on teaching a problem solving skillset to employees that they can in turn use to assess, diagnose, and treat problems that occur in their everyday work. This educational program was created with two main arms: a three day face to face workshop and an online elearning certification component.

The didactic portion of the training program relies heavily upon simulation and group work to teach and reinforce through demonstration and hands on utilization of the tools presented by the instructor. Participants learn techniques for crafting objective problem statements, mapping a process 
and various methodologies for changing and sustaining their work environments. In addition to the methods taught for addressing workplace systems issues, a storyboarding technique is strongly emphasized. Participants learn how to illustrate processes and data for an entire project on an A3 size sheet of paper. Upon completion of the three day didactic course, the learner is prepared to return to their work environment and participate in a process improvement initiative as well as document their efforts on the A3 storyboard.

In order to keep people engaged with improvement work for longer durations beyond the didactic coursework and their first workplace project, an elearning component was added that would require a more interactive and prolonged exposure to the material being taught. A certification program was established to fulfill this need. The elearning course environment was set up online utilizing the Blackboard $^{\mathrm{TM}}$ software package. Upon successful completion of the didactic course, students were given instructions for how to register for and access the online course. Once registered, students could then begin to progress through the self-paced certification program. Within the program, there are three key components that link the didactic learning to the practical application of Systems Redesign. The first component is a narrative description of the improvement project that they contributed to after completion of the didactic coursework. This is a standard reporting form that can be downloaded from the online course environment, completed electronically, and then resubmitted for further evaluation. The second component is the electronic submission of a completed A3 storyboard as described previously. Again, a template and a sample completed project can be downloaded from the online course environment. Both documents will be submitted through the Blackboard ${ }^{\mathrm{TM}}$ software and graded by Purdue University course faculty. The third and final component is a multiple choice examination. The exam is designed to reinforce not only the didactic course knowledge but to focus more heavily on assessing the level of application of these methodologies in the improvement work that was performed. The exam only registers a "Pass" or a "Fail" result to the student and may be taken as many times as required to obtain a "Pass". The goal is not to intimidate the student or to force studying of printed materials but for the learner to obtain mastery of the content.

A critical success factor of the online course environment is the ability to interact closely with peers and instructors. While the students are working to fulfill the requirements of the certification, they have the ability to submit draft copies of all of their materials for review by the Purdue University course faculty, edits and feedback. This process not only helps to continually reinforce the methodologies that were taught in the classroom but it also ensures that they are being applied appropriately in the workplace. After students complete the didactic classroom session, they have the added support of the online course environment to facilitate the execution of their improvement projects in their workspace. Another important success factor is that the end result of the elearning portion of the education is a certification of completion in Systems Redesign methodologies. As opposed to any number of other online tools utilized to help students engage with each other and instructors, this course environment has the additional incentive of working towards a final goal of certification granted by Purdue University.

Since its inception in 2009, this program has enrolled 577 students and 301 have completed their certification. While this is a large number of professionals working to better patient care, the real success lies in the improvement that is represented by 301 certifications. The great diversity of projects completed prevents any universal metric from being applied to show a single outcome, but volume 
alone shows significant investment made beyond the didactic classroom experience. Overall, the elearning environment leveraged in this program can bridge traditional classroom education and practical implementation of new skills resulting in the certification of professional competency in Systems Redesign.

\section{The Medication Safety Essentials Continuing Education Modules}

Medication safety has become an increasingly important topic among health care providers in recent years. Dr. Hultgren and Dr. Hertig from the CMSA in collaboration with Pamela Karagory from the Purdue University School of Nursing recognized an opportunity to further knowledge in this area and create online educational modules in hope of providing health care professionals a fundamental understanding of safe medication use practices. The Medication Safety Essentials Certificate Course is comprised of seven modules tailored to physicians, pharmacists, nurses, and health-system safety/quality professionals whereby each profession can earn up to seven continuing education credits. The state of Iowa now requires that pharmacists receive two continuing education credits (of the 30 required to renew one's license) related to Medication Safety [12]. Florida and New York are similarly structured, requiring two hours and three hours, respectively, in a continuing education course addressing how to reduce medication errors.

The goal of the Medication Safety Essentials Course is to guide the learner through every major step in the medication use system. Each module will not only educate the learner in a specific topic, but will also introduce tools and methods to improve safety in their own practice. The content, housed on Blackboard ${ }^{\mathrm{TM}}$ software, provided in all seven elearning modules is listed in Table 1. There are three learning objectives associated with each Medication Safety Essentials module that the instructors will meet, also found in Table 1. In order for each participant to complete and receive credit for the seven elearning modules, each participant must (1) view the video with the corresponding slide deck, (2) complete the post-test with a minimum of 70\% passing score, (3) complete the provided evaluation, (4) complete the request for credit with an estimation of time spent. Upon completion of those four requirements, certificates of credit and pharmacy credits for continuing education will be sent via email or uploaded to Continuing Pharmacy Education (CPE) Monitor — an eportfolio — within four weeks.

These seven modules Purdue University offers are accessed online for a fee and delivered to the individual's electronic device (i.e., computer, iPad, tablet) as an entire course. The learning portion, of the course, is described in (1) above, as the professional must watch a video of either Dr. Hertig, Dr. Hultgren, or Ms. Karagory presenting content from the associated slide presentation. This is similar to the lecture style seen in most teaching institutions, however, the subject matter can now be conveniently viewed from anywhere an electronic device can stream the video. The next components for certification described in $(2,3,4)$ above are also accessed online in a self-paced format from the course. Learners are expected to take an examination after completion of each module. Answers are recorded internally and a score is computed. This allows the professional taking the exam to receive immediate feedback on how they performed on that particular section, and if a score of $70 \%$ was not achieved, they are allowed additional opportunities to review the material and re-take the courses post-test. The completion of each elearning module's evaluation and request for credit is also housed within the course for convenience. Once all four components are finished and submitted, the learner will be 
notified that all seven elearning modules (Table 1) have been completed and that their credit certificates for continuing education will be sent electronically to the provided email address.

Table 1. Medication safety essentials module content.

\begin{tabular}{|c|c|}
\hline $\begin{array}{l}\text { Module } \\
\text { Numbers }\end{array}$ & Module Content \\
\hline \multirow{4}{*}{ Module 1} & Medication Safety Essentials- Medication Errors \& Safety Practices \\
\hline & Identify system errors that contribute to the cause of medication errors \\
\hline & Describe the social and economic impacts of medication errors \\
\hline & Outline methods that can be utilized to decrease the incidence and severity of medication errors \\
\hline \multirow{4}{*}{ Module 2} & Medication Safety Essentials- Errors in Prescribing and Transcribing \\
\hline & Identify the common error-prone situations in the prescribing process \\
\hline & Describe verbal and written transcription errors that occur in healthcare \\
\hline & Outline methods used to prevent prescribing and transcribing errors \\
\hline \multirow{4}{*}{ Module 3} & Medication Safety Essentials- Errors in Dispensing \\
\hline & Identify potential sources of dispensing errors \\
\hline & Describe strategies to minimize the likelihood of dispensing errors \\
\hline & Design a specific action plan to mitigate dispensing errors \\
\hline \multirow{4}{*}{ Module 4} & Medication Safety Essentials- Errors in Administration and Monitoring \\
\hline & Recognize the types of administration errors that can occur \\
\hline & Develop strategies to prevent administration errors from occurring \\
\hline & Discuss the importance of obtaining patient information and communication in patient mentoring \\
\hline \multirow{4}{*}{ Module 5} & Medication Safety Essentials- Continuous Quality Improvement \\
\hline & Discuss why continuous quality improvement (CQI) is essential for healthcare professionals \\
\hline & Identify key components of the CQI process \\
\hline & Apply CQI tools in improving processes \\
\hline \multirow{4}{*}{ Module 6} & Medication Safety Essentials- Metrics, Scorecards, and Dashboards \\
\hline & Discuss the differences between dashboards, scorecards, and metrics \\
\hline & Describe how dashboards, scorecards, and metrics can be used to improve medication use processes \\
\hline & Outline how to build a medication safety dashboard for your practice \\
\hline \multirow{4}{*}{ Module 7} & Medication Safety Essentials- Leading for Safety \\
\hline & $\begin{array}{l}\text { Evaluate the role of the leadership in advancing safe practices and how it aligns with your } \\
\text { professional career }\end{array}$ \\
\hline & Explain the importance in ensuring organizational leadership is aligned with a culture of safety \\
\hline & Develop a plan for you to improve the safety of the care you provide \\
\hline
\end{tabular}

When participants complete these elearning modules, they provide a deeper understanding of the medication-use process and a basic knowledge on ways to measure in order to enhance safety. Participants can receive a validated and recognized certificate that will account for seven continuing education courses in which they can apply to their State's biennial licensing requirements. In addition, by encouraging a health-care institution to partake in these courses as a team, it enables their employees to speak the same language when discussing safe medication use practices. As medication safety specialists, providing a common language will hopefully increase communication for an outcome of decreased medication errors and increased process improvements. 


\section{The Virtual Pharmacy Cleanroom Simulation Certificate}

Pharmacists serve a vital role by ensuring that the right patient receives the right medication through involvement in every step of the medication use process, including the compounding and verification of sterile products; pharmacists involved in sterile compounding have an error rate of approximately $10 \%[13,14]$. Therefore, providing pharmacists and pharmacy technicians with adequate instruction to prevent medication errors in a sterile environment is critical, and must include practice-based training within an intravenous (IV) room setting [15]. As a result, a virtual pharmacy cleanroom laboratory was launched and built (a three meter by three meter space with three connected white partitions where the simulation modules could be screened) at Purdue University in West Lafayette, Indiana, USA. The purpose of this virtual laboratory is to train pharmacy students on aseptic techniques and United States Pharmacopeia Chapter $797<$ USP 797> regulations which are designed to guide the safe use and compounding of sterile medications, and to cultivate student confidence in preparing IV medications appropriately. The development, implementation, and success of this virtual cleanroom environment have been published previously in the literature [16]. Despite the innovation and success of this virtual cleanroom environment, a major challenge remained. Due to the nature of the platform, the virtual laboratory is not able to be moved or transported; as a result, access to the benefits of this technology is limited to Purdue University students and those willing to travel to West Lafayette.

To overcome this barrier, while maintaining high quality educational programing, elearning is being used to launch a web-based virtual cleanroom series designed to be accessible anywhere in the world. This eight-hour virtual course is currently in development and will be maintained by Purdue University. The two primary objectives of the course are (1) to focus on $<$ USP 797>; and, (2) prepare students and health professionals for working and interacting within an IV clean room. To meet these primary course objectives, a course structure has been developed and includes eight, one-hour, self-paced, online modules, as shown in Table 2.

Table 2. The virtual pharmacy cleanroom series module content.

\begin{tabular}{|c|c|}
\hline $\begin{array}{l}\text { Module } \\
\text { Number }\end{array}$ & Module Content \\
\hline \multirow{5}{*}{ Module 1} & Overview of the Cleanroom \\
\hline & Determine the correct gowning order given a list of required items \\
\hline & Compare vertical and horizontal flow hoods \\
\hline & Recite proper alcohol content needs to thoroughly clean a laminar flow hood \\
\hline & Use concepts to describe unidirectional flow in a laminar hood and its purpose \\
\hline \multirow{5}{*}{ Module 2} & Aseptic Technique \\
\hline & Identify critical-area contamination factors \\
\hline & $\begin{array}{l}\text { Locate critical sites while compounding and recommend strategies to minimize critical } \\
\text { site contamination }\end{array}$ \\
\hline & Apply aseptic technique concepts to compound products in a virtual cleanroom \\
\hline & Differentiate between sterile technique and aseptic technique \\
\hline
\end{tabular}


Table 2. Cont.

\begin{tabular}{|c|c|}
\hline $\begin{array}{l}\text { Module } \\
\text { Number }\end{array}$ & Module Content \\
\hline \multirow{5}{*}{ Module 3} & Managing Risk Levels \\
\hline & List the three sources of contamination (people, equipment, and environment) \\
\hline & Determine the level of risk associated with a preparation when presented with a clinical case \\
\hline & Distinguish type of parental products. (Intramuscular, Intravenous, Intrathecal, etc.) \\
\hline & Identify the various routes of administration and their general characteristics \\
\hline \multirow{5}{*}{ Module 4} & Compounding in a Cleanroom \\
\hline & Perform a virtual IV dilution using sterile technique \\
\hline & $\begin{array}{l}\text { Show how to properly transfer contents from a single vial and ampule, using filtration, to } \\
\text { an IV bag }\end{array}$ \\
\hline & $\begin{array}{l}\text { Assess a product for stability, compatibility, defects, and expiration date and product } \\
\text { integrity before use }\end{array}$ \\
\hline & $\begin{array}{l}\text { Execute aseptic preparation procedures, proper gowning and gloving technique, and correct } \\
\text { general conduct in an IV cleanroom }\end{array}$ \\
\hline \multirow{4}{*}{ Module 5} & Proper Clean-up and Disposal \\
\hline & Develop a standard process for proper disposal of waste after sterile product preparation \\
\hline & Demonstrate proper biohazard clean up procedures \\
\hline & Understand the risks associated with improper disposal \\
\hline \multirow{4}{*}{ Module 6} & Product Selection \\
\hline & $\begin{array}{l}\text { Determine the chemical compatibility, stability, and overall properties of the active } \\
\text { ingredient when provided with the proper resources }\end{array}$ \\
\hline & Select the appropriate ingredients for IV preparation \\
\hline & Accurately compute and analyze sterile compound calculations \\
\hline \multirow{5}{*}{ Module 7} & Product Verification \\
\hline & $\begin{array}{l}\text { Explain and identify medication safety concerns associated with verification of a sterile } \\
\text { product }\end{array}$ \\
\hline & State what is necessary for product verification and why product verification is important \\
\hline & Quote the information desired on an IV label \\
\hline & Validate a product preparation for accuracy \\
\hline \multirow{4}{*}{ Module 8} & Documentation and wrap up \\
\hline & $\begin{array}{l}\text { Produce a final recommendation for the preparation and administration of an IV product } \\
\text { that is safe and accurate based on an assigned medication problem }\end{array}$ \\
\hline & Construct appropriate sterile product compounding documentation \\
\hline & $\begin{array}{l}\text { Identify causes and solutions to medication safety risks associated with compounding } \\
\text { medications in an IV cleanroom }\end{array}$ \\
\hline
\end{tabular}

To complete this course, the student will enroll in the Purdue University Virtual Pharmacy Cleanroom Series online program. Instruction is given through a combination of virtual cleanroom experience, case-based problem sets, required readings, lectures, and interactive learning sessions. Each didactic lecture will be presented online in a pre-recorded format and supplemented with practice-based experience in the virtual cleanroom computer simulation. Similar to simulations or video-games, the student will be able to use their personal or work electronic device via the keyboard to enter a pharmacy clean room wherever they are in the world. Through this environment, the student 
will encounter a variety of case-based scenarios and problem sets that they will have to navigate through and complete on the electronic device with the keyboard functions, including:

- Proper hand-washing and garbing procedures

- Medication calculations and compounding

- Cleanroom object and inappropriate object identification

- Cleaning and disinfecting laminar and vertical flow hoods

- Proper cleanliness and disposal of waste

- Product selection and verification

- Cleanroom process flow and medication safety considerations

To complete each module the student will need to demonstrate competency through a combination of post-lecture test questions, practice-based virtual scenarios, and basic material comprehension tests throughout their experience in the virtual environment. A certificate of completion from Purdue University shall be awarded after successful completion of all required modules.

There are many benefits of this innovative and advanced approach to sterile environment teaching. Unlike the original virtual platform that could not be transported or accessed easily, this online elearning-based program is accessible to anyone in the world. The course content ensures the learner is taught a standardized and literature-based approach to safe medication use in a sterile environment. Integrating both didactic and practice-based learning and assessment leads to a high level of competency upon completion of the eight, one-hour modules. Ultimately, this successful model of elearning affords any health professional the opportunity to access, learn, and practice critical clean room principles and skills in a safe, virtual environment, minimizing the risk to patients and enhancing skill-focused training and education.

\section{Results and Discussion}

Three different elearning opportunities have been described that provide educational mobility, career advancement, and/or professional development for pharmacists and other healthcare professionals. By learning and accessing knowledge and skills through elearning, learners have more opportunities to develop the competencies needed in pharmacy and other healthcare professions. Today's learners are technology-savvy; learners come into higher education knowing the technology as well as typically having used these platforms in other educational settings.

Access to learning and obtaining professional development becomes more accessible and flexible for today's students and professionals. Additionally, elearning has been found to be neither superior nor inferior to traditional modes of learning, as discovered by Cook et al. Many people prefer internet based functionality and elearning provides access $24 / 7$ in any location [17]. It is now easier to update skill sets, to acquire new knowledge, and to demonstrate competency through elearning environments. These three exemplars - the Yellow Belt Lean Certificate, the Medication Safety Essentials Certificate, and the Virtual Pharmacy Cleanroom Simulation Certificate offerings-demonstrate educational modalities that (a) assist the learner to keep abreast of new knowledge, (b) provide a mechanism to learn and review knowledge and skills, and (c) create a method to standardize knowledge and skills to health professionals such as pharmacists. 
Healthcare professional educators continuously seek opportunities to incorporate an expanding body of knowledge, skills, and new initiatives into a curriculum that is already condensed with content. By providing elearning opportunities on selected important topics to students to learning outside of class time, it provides a flexible method to deliver the content needed. Many colleges and universities across the world are discovering innovative and exciting ways of using instructional technology to promote the process of teaching and learning and to extend the education to new populations of students. With the advent of the massive, open, online courses (MOOCs), accessing education to gain knowledge and skills is being revolutionized. These elearning modules and programs described to teach health professionals essential skills and provide required knowledge in their discipline demonstrate a few examples of how higher education is currently changing and the direction education is moving in the near future. The challenge is to prepare comprehensive, high quality content for cost effective programs of learning so educational standards and competencies can be met as demonstrated by these three examples in pharmacy.

\section{Conclusions}

Ongoing assessment and research is needed as these technological advances and new pedagogical approaches are developed to ensure that new technologies do not compromise the quality of education and clinical practice of our healthcare professionals. As with any program of instruction, evaluation is a necessary component of the online teaching process. It is important to measure the learning outcomes and student achievement.

\section{Acknowledgments}

Authors would like to acknowledge the work of Steve Abel and Steve Dunlop, both of Purdue University for their contributions to the Virtual Pharmacy Cleanroom Series project, along with George Takahashi and his colleagues at The Purdue University Envision Center for Data Perceptualization.

\section{Conflict of Interest}

The authors declare no conflict of interest.

\section{References}

1. Classen, D.C.; Pestotnik, S.L.; Evans, R.S.; Lloyd, J.F.; Burke, J.P. Adverse drug events in hospitalized patients. J. Am. Vet. Med. Assoc. 1997, 277, 301-306.

2. Cullen, D.J.; Sweitzer, B.J.; Bates, D.W.; Burdick, E.; Edmondson, A.; Leape, L.L. Preventable adverse drug events in hospitalized patients: A comparative study of intensive care and general care units. Crit. Care Med. 1997, 25, 1289-1297.

3. Cullen, D.J.; Bates, D.W.; Small, S.D.; Cooper, J.B.; Nemeskal, A.R.; Leape, L.L. The incident reporting system does not detect adverse drug events: A problem for quality improvement. Joint. Comm. J. Qual. Im. 1995, 21, 541-548. 
4. Bates, D.W.; Spell, N.; Cullen, D.J.; Burdick, E.; Laird, N.; Petersen, L.A.; Small, S.D.; Sweitzer, B.J.; Leape, L.L. The costs of adverse drug events in hospitalized patients. J. Am. Vet. Med. Assoc. 1997, 277, 307-311.

5. Bates, D.W.; Cullen, D.J.; Laird, N.; Petersen, L.A.; Small, S.D.; Servi, D.; Laffel, G.; Sweitzer, B.J.; Shea, B.F.; Hallisey, R.; et al. Incidence of adverse drug events and potential adverse drug events. J. Am. Vet. Med. Assoc. 1995, 274, 29-34.

6. Raschke, R.A.; Collihare, B.; Wunderlich, T.A.; Guidry, J.R.; Leibowitz, A.I.; Peirce, J.C.; Lemelson, L.; Heisler, M.A.; Susong, C. A computer alert system to prevent injury from adverse drug events. J. Am. Vet. Med. Assoc. 1998, 280, 1317-1320.

7. Thomas, E.J.; Studdert, D.M.; Newhouse, J.P.; Zbar, B.I.; Howard, K.M.; Williams, E.J.; Brennan, T.A. Costs of medical injuries in Utah and Colorado. Inquiry 1999, 36, 255-264.

8. Institute of Medicine. To Err Is Human: Building a Safer Health System; Kohn, L.T., Corrigan, J.M., Donaldson, M.S., Eds.; National Academy Press: Washington, DC, USA, 2000.

9. Institute of Medicine. Crossing the Quality Chasm: A New Health System for the 21st Century; National Academy Press: Washington, DC, USA, 2001.

10. Institute of Medicine. Preventing Medication Errors: Quality Chasm Series; National Academy Press: Washington, DC, USA, 2006.

11. Maxwell, S.; Mucklow, J. E-learning initiatives to support prescribing. Brit. J. Clin. Pharmaco. 2012, 74, 621-631.

12. Iowa Board of Pharmacy: Continuing Education. Available online: http://www.state.ia.us/ibpe/ pharmacists/continuing_education.html (accessed on 28 June 2013).

13. US Food and Drug Administration. Limited FDA Survey of Compounded Drug Products. Available online: http://www.fda.gov/Drugs/GuidanceComplianceRegulatoryInformation/ PharmacyCompounding/ucm155725.htm (accessed on 28 June 2013).

14. Flynn, E.A.; Pearson, R.E.; Barker, K.N. Observational study of accuracy in compounding i.v. admixtures at five hospitals. Am. J. Health-Syst. Pharm. 1997, 54, 904-912.

15. ASHP Council on Professional Affairs. ASHP guidelines on quality assurance for pharmacy-prepared sterile products. Am. J. Health-Syst. Pharm. 2000, 57, 1150-1169.

16. Patel, S.; Vincent, A.H.; Abel, S.R.; Jacobs, C.M.; Dunlop, S.R.; Seibert, M. A virtual clean room to teach USP 797 regulations for intravenous medications. Am. J. Pharm. Educ. 2011, 75, Article 7.

17. Cook, D.; Levinson, A.J.; Garside, S. Internet-based learning in the health professions: A meta-analysis. J. Am. Vet. Med. Assoc. 2008, 300, 1181-1196.

(C) 2013 by the authors; licensee MDPI, Basel, Switzerland. This article is an open access article distributed under the terms and conditions of the Creative Commons Attribution license (http://creativecommons.org/licenses/by/3.0/). 